This is the peer reviewed version of the following article: Josserand, E.L., Kaine, S., \& Nikolova, N. (2018). Delivering sustainability in suppy networks: Achieving networked multi-stakeholder collaborations. Business Strategy and the Environment, which has been published in final form at http://dx.doi.org/10.1002/bse.2065. This article may be used for non-commercial purposes in accordance with Wiley Terms and Conditions for SelfArchiving 


\title{
Delivering sustainability in supply networks: Achieving networked multi- stakeholder collaborations
}

\begin{abstract}
Fragmented supply networks involving a number of actors in the production and distribution of products and services are increasingly common. However, research on sustainability has so far not sufficiently addressed the question how to deliver sustainability strategies and practices across fragmented supply networks. In particular, existing research on sustainability in supply networks does rarely adopt a systemic perspective. Consequently, we know little about the ability of organisations to address the competing priorities characteristic for supply networks spanning organisational, cultural and geographical borders. This special issue contends that network dynamics can be transformative in how organisations address sustainability challenges. The series of papers in the special issue study novel approaches to sustainability adopting multi-stakeholders/multi-perspective approaches. Each of the papers presents specific examples of the issues arising in fragmented supply networks and outlines context-appropriate responses that can help overcome such fragmentation. In this introduction section, we propose a conceptual framework that integrates the key drivers or inhibitors of sustainable perspectives, practices, and metrics in supply chains. The model has implications for both theoretical research and organizational practice on sustainability in supply networks.
\end{abstract}

Keywords: Sustainability, Supply networks, Supply chains, Multi-stakeholder collaboration, Systemic perspective

Corporate sustainability encompasses a number of inter-related yet often competing demands (Wright and Nyberg 2017). Tensions between economic, social and environmental outcomes are not new but are becoming more of a focus with questions being raised about the hegemony of the 'business case thinking' that characterizes much of the academic research in this area (Hahn et al 2014). Such layers of complexity have prompted calls for corporations to reassess their core functions and purpose (Freeman 2017). For example, BCorp organisations are hybrids between profit and not for profits whose purpose is to create benefit for all stakeholders - shareholders, employees, community, and environment (https://www.bcorporation.net/what-are-bcorps/the-b-corp-declaration).

The ambiguities associated with sustainability, and its desirability, scope and implementation, are compounded when extending considerations of these issues beyond organisational boundaries. That is, the ability of managers to make sense of the competing priorities presented by the different dimensions of sustainability - including the economic one - is often complicated by 
engagement with intricate supply networks spanning organisational, cultural and geographical borders. A well-known example is Apple's failure to address pollution caused by its suppliers in China (https://www.reuters.com/article/usapple-china/apple-criticized-for-china-supply-chain-pollutionidUSTRE77U4M620110831). In such complex networks, each choice is characterized by the complexity of its consequences and escapes simple common business reasoning.

These tensions are complicated by theoretical frameworks and practices that are fragmented, thus favoring one aspect of sustainability while completely ignoring others. There has been an increased concern over the non-systemic basis of firm and industry focused research on sustainability (Whiteman et al., 2013). While integrated models have been proposed (Starik and Kanashiro, 2013; Benn et al., 2014) or are being developed, answering calls to challenge research dogma and propose new theoretical perspectives, there is still lack of "expertise and knowledge of how to organize and

facilitate the implementation of sustainability aspects in complex global industrial supply networks" (van Bommel, 2011: 896).

In this special issue, we have collected a series of papers that document current tensions based on the differences, distinctions and diversity of actors involved in supply chains and which study novel approaches to sustainability adopting multi-stakeholders/multi-perspective approaches. The rationale of this special issue is that by knowing better the lines of fragmentation between actors and by learning about new practices that can help overcome such lines of fragmentation, we can help renew theoretical approaches and support the delivery of sustainability in supply networks.

In this introduction, after providing a summary of the key contextual characteristics that are associated with the development of fragmented supply networks, we integrate the contributions of the special issue into a framework that helps think further how to deliver sustainability across complex and fragmented supply networks.

\section{A CONTEXT OF NETWORKED PRODUCTION}

In a local and global context of increased fragmentation of production, distribution and consumption, there is a need to rethink sustainability as a networked endeavour (e.g., van Bommel 2011).

\section{The fragmentation of supply networks}

Fragmentation of supply networks happens both at the local/national level and internationally (Lakhani et al., 2013). This trend is supported by resourcebased approaches in strategy research which prioritize core competencies and advocate the outsourcing of non-core activities (Prahalad and Hamel, 1990). This favors the creation of complex networks and value chains that can be characterized by bigger, powerful actors concentrating on high valueadded activities while lower value activities are subcontracted to smaller, less powerful actors, which are sometimes marginalized. 
National contexts have seen an increase of fragmentation of production and distribution in the form of recourse to various forms of outsourcing, including subcontracting, and the increased use of semi-independent workers and agency workers (Weil, 2014). In the case of semi-independent workers and agency workers, this is supported by deregulation of labour markets aiming to address competitive global pressures. For instance, nation states have felt compelled to deregulate their labour markets in order to increase labour flexibility and thus remain competitive. This approach has been widely adopted in Europe, Latin America and especially in Asia (Heery, 2009). Such contingent and vulnerable forms of work are often evident in local and global supply chains and global value chains.

A similar trend can be observed at an international level, where the international outsourcing/offshoring of production contributes to the development of even more complex supply networks. From an economic perspective, and beyond the strategic determinants mentioned above, this is explained by Ricardian models of vertical specialization leading to cost advantages. This results notably in the emergence of buyer-driven supply chains (Gereffi, 1994) where lead firms rely on global supply networks to produce labour-intensive products from suppliers located in low-labour cost, developing countries with lower ecological sensitivities (Barrientos et al., 2010).

\section{Regulation gap}

Since the broad diffusion of CSR ideas in the 80 's, there has been a heavy reliance on industry self-regulation or co-regulation. In some cases, companies' self-imposed codes of ethics and ethical practices or industry-wide standards have proven efficient and have contributed to the diffusion of more sustainable practices (Whiteman et al., 2013; Fremeth and Richter, 2011). However, we also know that self-regulation and co-regulation have so far been insufficient to deal with the scale of the issues (Wright and Nyberg, 2017).

Researchers have shown that several critical Earth system processes have breached their safe operating levels/boundaries: climate change, ocean acidification, and stratospheric ozone (Whiteman et al., 2013; Steffen et al., 2011). As Wright and Nyberg point out in a recent article published in the Academy of Management Review (2017: 1633), "Environmental change of this kind is unprecedented for our species, and climate scientists argue that such a future is likely to be incompatible with human civilization". These challenges are unlikely to be successfully addressed through industry self-regulation and in the absence of a systemic approach involving both corporations and governments.

As far as social standards are concerned, existing mechanisms, such as consumer pressure and activist networks (Wright, 2011; Donaghey et al., 2014) that seek to deprive unethical businesses of patronage, fail to address some of the most unacceptable labour issues. While international campaigns operate at a global level (den Hond and De Bakker, 2007; den Hond, Stolwijk and Merk, 2014), they remain challenging (Cheng et al., 2011) and are not as effective for unbranded goods where consumer power is weak (Donaghey et 
al., 2014). Company audits can assist in identifying unethical practices but do not consistently produce timely or lasting results (Egels-Zandén, 2014), especially as many companies fail to engage beyond the first levels of their value networks, neglecting components or raw materials, for instance (Apple is again an often cited example).

There is thus a regulation gap, where self- and co-regulation as it currently happens is insufficient to drive a change to our practices. This is partly due to the fragmentation of production and distribution, meaning that neither state action, civil organization activism, labour power nor consumer action can match the power of capital (Donaghey et al., 2014). Public agencies or isolated actors cannot generate change or tackle non-compliance issues on an ad-hoc, case by case basis; new forms of regulation are needed to trigger systemic effects that cannot be obtained through disjointed efforts (Wright and Nyberg, 2017). We argue that the inherent multi-scalarity and fragmentation in global value networks necessitates such a systemic approach to social and environmental standards by the various stakeholders concerned, thus reflecting the focus of this special issue on the network dimension.

\section{Network effects}

The contributions of this special issue embrace a general idea that network dynamics can be transformative and thus contribute to address some of the limitations of current regulatory mechanisms and organisational responses to the above discussed sustainability challenges. The papers in the special issue directly address how cooperation between multiple actors can foster network dynamics leading to systemic transformation. Researching collaborative practices (Josserand et al., 2004) between institutional actors including governments, unions, NGOs, businesses, as well as more agile civil society actors, such as grass-root activist networks, is of great importance to understanding possible transitions towards more systemic approaches to change of current unsustainable practices.

We contend that organisations in supply networks currently fail to leverage the transformative power of networks because they fail to fully embrace the power of networks and their transformative force as social actants. Extant literature calls for further investigation of multiple stakeholder collaborations across the value network (Flanagin et al., 2006; van Bommel, 2011; Donaghey et al., 2014; Wilkinson et al., 2014), which is where the contribution of this special issue lays.

\section{MULTI-STAKEHOLDERS COLLABORATIONS: AN INTEGRATIVE FRAMEWORK}

In this section, we integrate the contributions in this special issue into a framework that helps further conceptualize how to deliver sustainability across complex and fragmented supply networks. We first distinguish four different types of tensions that characterize sustainability issues in supply networks. We then explore how reframing and the operationalization of sustainability can 
assist the organizations participating into supply networks to overcome such tensions (cf Figure 1).

\section{Insert Figure \\ 1 here}

\section{TENSIONS IN SUSTAINABLE SUPPLY NETWORKS}

We distinguish four different types of tensions that characterize sustainability issues in supply networks: contradictory objectives, institutional heterogeneity, strategic games and decoupling.

\section{Contradictory objectives}

A fundamental tension that stems from complex supply networks results from the classic trade-off between economic value creation for individual organizations and the aspiration, often by some rather then all participants, to achieve broader environmental and social goals (e.g., van der Linden and Freeman, 2017). This classic tension is well represented in Perey et al.'s argument in this issues about the tension between accepting the notion of limited resources available on our planet and the logic of growth and business performance that dominates business approaches to production. Brennan and Tennant's contribution also exposes how such trade-offs manifest in the UK brewery's malt supply network and how a restructuration of the network can help line up such contradictory objectives. In particular, they show how actors can partially converge in relation to some of their resources and objectives while they diverge on others, making a joint approach difficult and often only possible idiosyncratically. We add that the complexity and intricacies of supply networks combined with the multidimensional character of sustainability often not only create situations of tension between competing objectives but also situations where objectives can be contradictory and difficult to assess by managers and executives thus creating trade-offs (Hahn et al., 2010). For instance, delocalization enhances purchasing power in developed countries and industrial expansion in developing countries, while resulting in job losses in developed countries. Deregulation may promise increased employment but is often associated with increased precariousness and lower social standards and wages. Monitoring human and environmental sustainability along supply chains according to myriad codes of conduct may result in suspensions of non-complying suppliers with devastating social effects. Pursuing sustainability across the borders of global supply networks can lead to increased compliance costs that could have negative repercussions for actual social practices. Hence, tensions between objectives can emerge within or between organizations also in relation to the difficulty to make sense of what the "right" course of action would be for each organization or for the network because of the intricacies and potential contradictions between the outcomes of sustainability strategies (Hahn et al, 2010).

\section{Institutional heterogeneity}


Gaining clarity on network level objectives, even if actors agree on the validity of a sustainable approach, can be further complicated by the tensions between the institutional logics espoused by the actors - where institutional logics can be defined as "institutional patterns influencing beliefs and norms of action in organizations" (Quelin et al, 2017: p4). As Brown and Bajada remind us in their paper, such heterogeneity is frequent even among similar firms, for instance, firms with the same type of activities and operating in the same country. The authors refer to the research by Zhy et al (2010) as an example, demonstrating major differences across the manufacturing sector in China in terms of environment orientation. It is thus understandable that such tensions can be even more prevalent between actors belonging to radically distant institutional contexts.

Boersma's study explores how such differences between NGOs and MNCs can lead in divergences in the very definition of the issue of child labour between stakeholders. This is further complicated by the multiplicity of national and international definitions and norms of child labour contributing to tensions between NGOs and MNCs in their approach to risk, responsibility and appropriate actions. Such tensions make the establishment of multistakeholders collaborations complex and difficult. This tension between stakeholders' institutional logics has been observed in the context of publicprivate partnerships more generally, where the hybridity of institutional logics has been showed to complicate the resolution of tensions between objectives (Quelin et al, 2017; Caldwell et al, 2017).

\section{Strategic games}

Divergencies in objectives and institutional logics translate into strategic divergencies, games and tensions between stakeholders. In particular, stakeholders tend to continue pursuing their specific agenda while at the same time being conscious of the need to engage in collaborative practices at the level of the supply network. Brennan and Tennant's paper reinforces the importance of power games around sustainability in supply networks. Such games have the potential to thwart collaborative effort if stakeholders cannot escape the trade-offs between economic and broader objectives. However, power in supply networks can also be leveraged where specific firms have the capability to support collaborative endeavors leading to a reconfiguration of the supply network.

The outcome in terms of sustainability is highly dependent on how the normative aspirations of stakeholders are influenced by their political interactions. Boersma highlights the inherent tension that exists between the normative-ethical and the political/strategic aspects of any endeavor to construct multi-stakeholders collaborations. This is well illustrated in the case of child labour by the resulting tension between civil society organizations that tend to favor mandatory measures, and MNCs which tend to prefer selfregulation. In that case, it is very clear that the commitment of corporations to multiple-stakeholders collaborations is tamed by their strategic imperative to keep discretionary power. This can in some instances limit their capacity to participate in collaborative initiatives. This was well illustrated by the case of the Alliance for Bangladesh Worker Safety which emerged after the Rana 
Plaza disaster as a voluntary alternative for companies that did not want to sign onto the mandatary provisions of the Bangladesh Accord on Fire and Building Safety. The Alliance has been criticized for being controlled by companies and having limited transparency around reporting (Clean Clothes Campaign, 2016).

\section{Decoupling}

Another tension that emerges from the contribution of this special issue is that of decoupling. Decoupling corresponds to a tension between policies and their implementation and outcome, where the policies do not produce the results expected (Wijen, 2004). There are two forms of decoupling. First, as for instance in the case of "greenwashing", some stakeholders can be adopting policies and practices only ceremonially (Wijen, 2004), in some cases to even obscure contrary practices (Bartley \& Egels-Zandén, 2016). This tension between actual commitment and possibly ceremonial adoption is present in the picture painted by Boersma (this issue) of the ambiguous relationship between civil society organizations and MNCs when trying to establish multistakeholder collaborations. The data the author collected shows that while civil society organizations are convinced of the importance of business participation in order to tackle the issue of child labour in supply networks, they express doubts about the motivations of companies when contributing to multi-stakeholder initiatives as often companies act on the basis of opportunistic disclosure motives driven by a fear of reputational damage, rather than a genuine commitment to changing their practices.

The second form of decoupling is the "means-ends decoupling" where policies are in place but do not produce the expected outcomes, notably because they are disconnected from the specific contexts of implementation (Wijen, 2004). Boersma discusses the tensions about how to remedy child labour in global supply networks, suggesting the possibility for means-ends decoupling. For instance, civil society organizations doubt the efficacy of audits conducted merely by businesses and without the accreditation of a multi-stakeholder body. This is because without stakeholder consultation, approaches to child labour remain less effective. In the same vein, there is no consensus between actors on whether solutions that favor broad labour rights, such as freedom of association, rather than a strict child labour focus, are preferable. Brown \& Bajada (this issue) underline the difficulties in implementing a circular economy approach in the absence of adequate and context-specific modeling and metrics. This could contribute to means-ends decoupling where the strategies adopted risk is not producing the intended outcomes.

Altogether, the papers of this special issue suggest that existing tensions between policies and their implementation, and outcomes can result in serious risks of decoupling when attempting to make supply networks more sustainable.

\section{REFRAMING}

Reframing sustainability, notably to position it at the level of the network rather than at that of each individual stakeholder, features in all papers in this issue 
as an essential foundation when considering sustainable supply networks. Reframing, in the context of sustainability in supply networks, can be defined as reconceptualizing sustainability issues as emergent property of social processes that involve multiple actors in a wider network of business relationships (Perey et al this issue). Reframing is a change in worldview, a shift that Ison (2010) describes as learning from the experience of engaging in systems practice, i.e., it is driven by systems thinking.

Reframing appears to be a starting point for stakeholders to engage the idea of sustainability at the supply network level; however, reframing also happens on an on-going basis where operationalization of sustainability can induce further reframing. We distinguish four elements that could facilitate reframing of the issue of sustainability in supply networks: framing around an organizing concept and situation logics, an overarching policy, a contingent complementarity and a consensual practice. These four forms of reframing are not mutually exclusive.

\section{Framing concepts and logics}

Brennan \& Tennant's Bangladesh

paper explores how situational logics can help tackle the trade-offs between economic and social value. In their case study they show how a sustainabilityrelated logic could be substituted for the capitalist logic of spot-market that until then dominated the brewing industry. This change in logic was essential in triggering adjustments to the supply-chain and in moving from an organization of the supply chain through a focus on the spot market towards a sustainable integrated network. This new orientation allows capturing the "boundary-spanning" nature of value creation. In the same vein, Perey et al (this issue) describe the key role of organizing narratives developed in the eight organizations they studied. The authors argue that the organizations adopted principles of the circular economy which were reflected in three essential organizing narratives: obligation to nature, waste becomes a resource, and disruptive innovation. The reconceptualization of waste as a resource allowed the companies to shift their understanding of the place of waste and start considering radical changes that would ultimately lead them to appreciate the implications of a circular approach to their activities, in particular in viewing waste as a source of value. Consequently, these organizations could define new practices that could help overcome established practices based on a linear 'take-make-consume and dispose' logic.

\section{Policy}

While reframing around organizing concepts and situational logics is fundamental and can happen by means of self and co-regulation, an overarching policy can be very important in triggering change. Brown \& Bajada (this issue) remind us in their introduction of various initiatives and policies that have taken the framing concept of the circular economy to the next level. These include initiatives driven by business and other stakeholders, initiatives of cities, or national and international initiatives. Such policy efforts are essential in stimulating change and imposing new concepts triggering a rethink of supply networks sustainability. Indeed, unless the 
initiative comes from the lead firms of a specific supply network, individual organizations are often unlikely to be able to unilaterally introduce sustainable practices. The authors underline an interesting contrast between the ambitious sustainability policy undertaken by China and the relative silence of Australian policy on that matter. This is despite the fact that policies adopting circular economy principles can contribute not only to social value creation but also to economic value creation for the actors that are able to derive "wealth from waste" (Perey et al this issue). This is echoed by Boersma (this issue) who underlines the importance of the UN Guiding Principles in the development of norms regarding business responsibility in relation to child labour and more broadly other social and environmental issues.

\section{Contingent complementarity}

Brennan \& Tennant (this issue) show how situational logics can sometimes emerge that can help actors of a specific network define "win-win" solutions that are idiosyncratic and only apply in a specific collaboration of stakeholders. While the framing concepts and logics evoked above, such as the circular economy, are broadly defined and applicable in a large number of contexts, contingent complementarities capture the local translation of such concepts where this local translation allows for the concepts and logics to be accepted and create value in the specific context for all stakeholders involved. Contingent complementarity happens when existing resources of partners can be recombined to increase value because of network effects. It doesn't mean that generic concepts, in that case of sustainable supply networks, are not useful, but that their translation and localization allows for overcoming, at the level of the supply network, the trade-offs that exist in many contexts between economic and social value creation (Hahn et al, 2010).

\section{Consensual practice}

Finally, Boersma (this issue) describes, in the case of multiple stakeholder partnerships addressing child labor how some practices can be exempt from the normative-ethical/political strategic tension that characterizes many networks. In this case, the author found that the practices of human rights risk assessment and due diligence escape this tension. This is because businesses are pressed to adopt such practices because of increased norms of responsibility imposed globally, notably by the UN Guiding Principles, while civil society organizations also embrace the notion. This constitutes a fertile ground for collaboration beyond the possible skepticism of stakeholders in relation to business motivation, conflicting goals and risks of decoupling.

\section{IMPLEMENTATION OF SUSTAINABLE SUPPLY NETWORKS}

Reframing and implementation can happen simultaneously when new solutions emerge at the same time as new concepts start to make sense, however, it can also be a sequential process, where either of these two activities can come first. The authors of this special issue bring valuable insights to some of the pathways towards delivering sustainable supply networks and the changes that can support these networks. Such changes include changes in perspective, changes in practices and changes in metrics.

\section{Changing perspective: systemic thinking}


Perey et al (this issue) underline how a change in perspective can support the delivery of sustainable supply networks. They argue that the issue is one that requires managers to develop capabilities of systemic thinking (see also Ison 2010). Of course, such capabilities are not developed in a void of discourse and the emergence of new organizational narratives is essential to the development of such capabilities by managers. The shift from reframing the place of waste allows for a change of perspective that in turn helps managers think differently when strategizing; in this sense sustainability is both the product and the initiating concept of systemic thinking. Managers deliver sustainability in part because the narratives associated with sustainability enable them to become systemic thinkers. In particular, "[t]he sustainability perspective enables firms to analyse complex problems across multiple interacting sub-systems, to reframe the impacts and responsibilities of their activities and behaviours beyond their organisational boundaries, to include consideration of biospheric limits across their supply/value chains." (Perey et al,: x). This is directly operationalized in different approaches to production systems that can then be conceived as open rather then closed and self-contained, and allows to rethink the place of waste by repositioning the boundaries of an organization's span of control. The organizations Perey et al studied were thus able to innovate radically and rethink their operational process. There is thus a clear connection between the adoption of systemic thinking and the evolution of practices and control/metrics beyond organizational boundaries.

\section{Changing practices}

Other contributions of this special issue show different pathways for practices to change. Boersma describes how risk assessment and due diligence emerge as an area where common practices can emerge despite existing tensions between the stakeholders involved in collaborative efforts to solve the issue of child labor. In that case, the practice is the key driver for change and is closely associated with reframing. Brennan \& Tennant (this issue) suggest systematic approaches to making change happen in practice but also contribute to reframing. They show how business models for sustainability can favor the discovery of contingent complementarity, thus contributing to situational reframing and leading to new processes of sustainable value creation. Such business model innovation can happen at the level of the network, which is where former articulations of resources were institutionalized into pre-existing organization centric business models. The authors show how the core organization in their case leveraged the logic of sustainability to feed the reconfiguration of the business models at the network level.

\section{Changing metrics}

Finally, Brown and Bajada (this issue) discuss the importance of establishing metrics associated with targets and KPIs if the implementation of the redefined practices is to be successful. As argued by Perey et al (this issue), sustainable networks require a reconsideration of control and measures beyond the boundaries of the organizations that are part of supply networks. In the case of the circular economy framework, there is so far only limited formal analysis and metrics development that could enable proper monitoring of its implementation. Such metrics are important to track progress but also to 
provide benchmarks that can motivate stakeholders to further progress their sustainability goals.

\section{CONTRIBUTIONS/SUMMARY}

Combined the papers in this special issue contribute to the development of the integrative framework of multiple stakeholder collaborations in supply networks we have outlined above. Each of the papers offer contributions to the consideration of sustainability in supply networks. These are briefly summarized below.

Boersma's paper examines the tensions between the norms and practices of multi-stakeholder initiatives to eliminate child labour through the lens of civil society actors. He highlights that perceptions of supply chain auditing as ineffective and continuing arguments about the virtues of mandatory or voluntary regulation potentially undermine multi-stakeholder initiatives in the eyes of civil society actors. However, Boersma concludes that human rights risk assessments might provide an option for overcoming such negative perceptions.

In their paper, Brennan and Tennant present a case study of a UK brewer and its malt supply chain, emphasizing the power relations between the members of the supply chain and the implications of these for the enablement or inhibition of sustainable value creation. In particular they explore how network-centric business model innovation (BMI) resolves the trade-off between economic and environmental value.

Continuing the connection on business models with an environmental focus, Perey et al use systems thinking and the circular economy framework to explore the paradox of viewing waste as a burden and as a resource. Their findings reveal that those organizations that applied systems thinking to reconceptualize their services and products and engaged circular flows in their supply networks (specifically integrating waste as a resource) increased the value of their goods and services.

Brown and Bajada's contribution to this special issue also focuses on the Circular economy. Their paper highlights the challenge for stakeholders of monitoring and benchmarking sustainability performance in circular supply networks. The paper presents an economic model of material flow to assist in performance measurement across circular supply networks.

\section{CONCLUSION}

Establishing successful networked multi-stakeholder collaborations to deliver on sustainability is by no means an easy feat. Such networks face a range of tensions in addition to pursuing the paradoxical goal of delivering on multiple values of a range of stakeholders across institutional, geographical and cultural boundaries. However, the stakes for making supply chains more sustainable are high, with mounting evidence of the eminent destruction of our 
natural ecosystems that will have significant negative effects on organisations and societies.

The papers in this special issue seek to make a contribution towards our understanding of how supply networks can be made more sustainable. The contributions point out that there is not a one size fits all approach to achieving this goal. Rather, strategies for sustainability need to be developed by taking into account the specific characteristics of the networks/supply chains in question. Such strategies need to address the specific tensions existing in each network to then drive a context-appropriate reframing and implementation of new perspectives and practices. This requires a change in actors' cognitive orientation in accordance with systems thinking emphasizing the need to align collective network practices, policies and metrics with sustainable goals and values; a shift from focusing on individual organisations to collaborative systems of actors and recognizing the interdependent nature of network relationships.

The integrative conceptual framework on multi-stakeholder collaborations we propose seeks to explain how this shift can be achieved across complex and fragmented supply networks. Starting from the specific, contextual tensions organizations in the network/supply chain are facing, network members need to reframe the issue of sustainability in such a way as to make its operationalization through localized pathways possible. In addition, the proposed framework encourages researchers to focus on the network as a key driver of or barrier for sustainable strategies and to shed further light on the underlying mechanisms that either enable or inhibit the emergence of sustainable perspectives, practices, and metrics in supply chains. We see this special issue as an important step towards an integrated understanding of the role supply networks play in the delivery of sustainability.

\section{REFERENCES}

Barrientos S, Gereffi G, Rossi A. 2010. Economic and Social Upgrading in Global Production Networks: Developing a Framework for Analysis. Working Paper 2010/03.

http://www.capturingthegains.org/publications/workingpapers/index.htm [Accessed 19 February 2018]

Bartley T, Egels-Zandén N. 2016. Beyond decoupling: Unions and the leveraging of corporate social responsibility in Indonesia. Socio-Economic Review 14(2): 231-55. DOI: 10.1093/ser/mwv023

Benn S, Dunphy D, Griffiths A. 2014. Organisational Change for Corporate Sustainability, 3rd edition. Routledge: London and New York.

B Lab. 2018. 'The B Corp Declaration', https://www.bcorporation.net/what-areb-corps/the-b-corp-declaration [Accessed 19 February 2018]

Caldwell N.D., Roehrich J.K. George, G. 2017. Social Value Creation and Relational Coordination in Public-Private Collaborations. Journal of Management Studies, 54(6): 9906-928. 
Clean Clothes Campaign. 2016. Alliance for Bangladesh Worker Safety overstates progress while workers' lives remain at risk, Available at: https://cleanclothes.org/news/2016/11/21/alliance-for-bangladesh-workersafety-overstates-progress-while-workers-lives-remain-at-risk [Accessed 19 February 2018].

Cheng J.Y.S, Ngok KL, Huang Y. 2011. Multinational corporations, global civil society and Chinese labour: Workers' solidarity in China in the era of globalization. Economic and Industrial Democracy 33: 379-401. DOI: 10.1177/0143831X11411325

Den Hond F, De Bakker FGA. 2007. Ideologically motivated activism: How activist groups influence corporate social change activities. Academy of Management Review 32(3): 901-924. DOI: 10.5465/AMR.2007.25275682

Den Hond F, Stolwijk S, Merk J. 2014. A strategic interaction analysis of an urgent appeal system and its outcome for garment workers. Mobilization 19(1): 83-111.

Donaghey J., Reinecke J., Niforou C., \& Lawson B. 2014. From Employment Relations to Consumption Relations: Balancing Labor Governance in Global Supply Chains. Human Resource Management 53(2): 229-252.

Egels-Zandén N. 2014. Revisiting supplier compliance with MNC codes of conduct: Recoupling policy and practice at Chinese toy suppliers. Journal of Business Ethics 119(1): 59-75. DOI: 10.1007/s10551-013-1622-5

Flanagin AJ, Stohl C, Bimber B. 2006. Modeling the structure of collective action. Communication Monographs 73(1): 29-54. DOl:

10.1080/03637750600557099

Freeman RE. 2017. The new story of business: Towards a more responsible capitalism. Business and Society Review 122(3): 449-465. DOI:

10.1111/basr.12123

Fremeth AR, Richter BK. 2011. Profiting from environmental regulatory uncertainty. California Management Review 54(1): 145-165. DOI: 10.1525/cmr.2011.54.1.145

Gereffi G. 1994. The organization of buyer-driven global commodity chains: How U.S. retailers shape overseas production networks. In Commodity Chains and Global Capitalism, Gereffi G, Korzeniewicz M (eds); 95-122. Praeger: Westport, CT.

Hahn T, Figge F, Pinkse J, Preuss L. 2010. Trade - offs in corporate sustainability: you can't have your cake and eat it. Business Strategy and the Environment 19(4): 217-229. DOI: 10.1002/bse.674

Hahn T, Preuss L, Pinkse J, Figge F. 2014 Cognitive frames in corporate sustainability: managerial sensemaking with paradoxical and business case frames. Academy of Management Review 39(4): 463-487. DOI: 10.5465/amr.2012.0341

Heery E. 2009. Trade unions and contingent labour: Scale and method. Cambridge Journal of Regions, Economy and Society 2: 429-442. DOI: $10.1093 /$ cjres/rsp020 
Idowu SO, Capaldi N, Zu L, Gupta AD (Eds.). 2013. Encyclopedia of Corporate Social Responsibility. Springer Berlin Heidelberg: Berlin, Heidelberg.

Ison R. 2010. Systems Practice: How to Act in a Climate-Change World. Springer: London UK.

Josserand E, Clegg SR, Kornberger M, Pitsis T. 2004. Friends or Foes?

Practicing Collaboration. M@n@gement 7(3): 37-45. DOI:

10.3917/mana.073.0037

Lakhani T, Kuruvilla S, Avgar A. 2013. From the firm to the network: Global value chains and employment relations theory. British Journal of Industrial Relations 51(3): 440-472. DOI: 10.1111/bjir.12015

Martina M. 2011. Apple criticized for China supply chain pollution. Reuters, \#TECHNOLOGY NEWS, September 1, 2011. Available at:

https://www.reuters.com/article/us-apple-china/apple-criticized-for-chinasupply-chain-pollution-idUSTRE77U4M620110831 [Accessed 20 Jan 2018].

Prahalad CK, Hamel G. 1990. The core competence of the corporation. Harvard Business Review: Boston (Ma).

Quelin B.V., Kivleniece I., Lazzarini S. 2017. Public-Private Collaboration, Hybridity and Social Value: Towards New Theoretical Perspectives. Journal of Management Studies, 54(6): 763-792.

Starik M, Kanashiro P. 2013. Toward a theory of sustainability management: Uncovering and integrating the nearly obvious. Organization \& Environment, 26(1), 7-30. DOI: 10.1177/1086026612474958

Steffen W, Persson A, Deutsch L, Zalasiewicz J, Williams M, Richardson K, Crumley C, Crutzen P, Folke C, Gordon L, Molina M, Ramanathan V, Rockström J, Scheffer M, Schellnhuber HJ, Svedin U. 2011. The Anthropocene: From global change to planetary stewardship. Ambio 40(7): 739-761. DOI: 10.1007/s13280-011-0185-x

Van Bommel HW. 2011. A conceptual framework for analyzing sustainability strategies in industrial supply networks from an innovation perspective. Journal of Cleaner Production 19(8): 895-904. DOI: 10.1016/j.jclepro.2010.12.015

Van der Linden B, Freeman RE. 2017. Profit and other values: Thick evaluation in decision making. Business Ethics Quarterly 27(3)1-27. DOI: 10.1017/beq.2017.1

Weil D. 2014. The Fissured Workplace, Why Work Became So Bad for So Many and What Can Be Done to Improve It. Harvard University Press: Cambridge MA.

Wijen F. 2014. Means versus ends in opaque institutional fields: Trading off compliance and achievement in sustainability standard adoption. Academy of Management Review. 39: 302-23. DOI: 10.5465/amr.2012.0218

Wilkinson A, Dundon T, Donaghey J, Townsend K. 2014. Partnership, collaboration and mutual gains: evaluating context, interests and legitimacy. 
The International Journal of Human Resource Management 25(6): 737-747. DOI: 10.1080/09585192.2014.868713

Whiteman G, Walker B, Perego P. 2013. Planetary boundaries: Ecological foundations for corporate sustainability. Journal of Management Studies 50(2), 307-336. DOI: 10.1111/j.1467-6486.2012.01073.x

Wright C, Nyberg D. 2017. An inconvenient truth: How organizations translate climate change into business as usual. Academy of Management Journal 60(5): 1633-1661. DOI: 10.5465/amj.2015.0718

\section{Figure Legends}

Figure 1: An integrative framework of multi-stakeholder collaborations in supply networks 